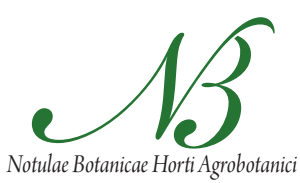

Cluj-Napoca

\title{
Variation in Seed and Seedling Traits among Fifteen Chinese Provenances of Magnolia officinalis
}

\author{
Xiao SHU, Xu YANG, Zhiling YANG* \\ Research Institute of Subtropical Forestry, Chinese Academy of Forestry, Fuyang 311400, \\ Zhejiang, China; zlyang0002@126.com ("correspondingauthor)
}

\begin{abstract}
Magnolia officinalis seeds were collected from 15 different provenances, ranging from 336 to $1387 \mathrm{~m}$ in China. The main objective of this study was to identify germplasm resources of $M$. officinalis by test seed traits, seed germination, seedling traits, and seedling growth rate. There are significant differences among provenances in all studied attributes except relative growth rate and the net assimilation rate. Seed weight exhibited maximum variation among provenances in seed morphometric traits with a significant positive correlation in terms of average annual temperature and average annual rainfall, and negative correlation with latitude of seed origin. Overall average seed germination in nursery was $59.4 \%$ varying from $26.6 \%$ to $91.2 \%$. Seedling height decreased by geographical latitude gradually from south to north, while stem diameter declines from east to west. That means the geographic variation of the plant at the seedling stage manifests a two-way variation with the latitude and longitude. Seed of Longsheng, Yangxian, Jingning, Wuyishan, Kaixian and Ningqiang provenance have been identified suitable to produce quality seedlings. It can be concluded that the observed patterns of variation will have implications for genetic resources conservation and tree improvement.
\end{abstract}

Keywords: net assimilation rate, provenances, relative growth rate, seed germination, seed morphology

\section{Introduction}

Magnolia officinalis, a deciduous tree propagated from seeds and a traditional Chinese medicinal plant, is distributed throughout the subtropics in China at the range of 300-2,000 $\mathrm{m}$ in elevation ( $\mathrm{Fu}, 1992$ ). Individual plants may show some differences in leaf morphology across different fields. It is typically distributed in subtropical broadleaf forests, flowering from April to May and fruiting in October. The medicinal properties of the plant reside in its bark. The effective ingredients of $M$. officinalis are mainly phenols and alkaloids, of which magnolol and its isomer honokiol absolutely dominate (Shu et al., 2010), is one of the most important constituents of the crude drug prescriptions which are used for the therapy of neurosis, various nervous disorders, including Parkinsonism, and gastrointestinal abnormality (Tong et al., 2002).

Historically, a substantial number of wild populations existed, and were enough to satisfy domestic demands for the cortex. However, in the 1970s, major regions of $M$. officinalis habitat, largely mixed forest, were cut down. As a result, the distribution of wild populations rapidly declined. The species is particularly vulnerable due to its slow initial growth rate and late reproductive maturity. Because of its vulnerable status, $M$. officinalis was listed in the China red data book of plants (Fu, 1992). As one of the more important Chinese medicinal materials, $M$. offcinalis has been widely studied. Most studies have focused on effective ingredients, and pharmacology among others (e.g. Tong et al., 2002). In a traditional opinion, quality of the medicine is mainly influenced by environmental conditions of the producing area, such as climate and soil.

A critical decision in forest resource management is the choice of seed sources for reforestation to ensure a successful crop. Seed zones and seed transfer are essential tools in assisting this decision in order to avoid planting poorly adapted trees (Hamann et al., 2000). Verzino et al. (2003) have been suggested to provide guidelines for seed transfer for afforestation and reforestation. Select seed material used in germination is subject of local provenances, because they are expected to be better adapted to local environment conditions facilitating vegetation establishment (Hufford and Mazer, 2003). Selection is expected to favor appropriate responses to local environmental cues that synchronize germination with periods that are optimal for seedling survival. Such a selection may result in sitespecific adaptation of germination traits (Bischoff, 2006). Variation in germination behavior that occurs among different populations within the same species has been widely reported (e.g., Marova, 2010). The inter-population variability in germinability can be due to environmental differences or to genetic variation. Indeed, inter-population seed dormancy variability can serve as an adaptation strategy in unpredictable environments (Cruz et al., 2003; GiménezBenavides, 2005). Cultivation is an ongoing artificially selected process that occurs over time as humans select and cultivate wild plants (Hancock, 2004). The resulting founder effect, coupled with ongoing selection of seeds 
from the initial pool of cultivated genotypes, produced a genetic bottleneck in cultivated populations (Miller and Schall, 2006; Zohary, 2004).

Significant provenance variation in seed has been observed in different agroforestry tree species (Meskel and Sinclair, 2000), there should also be clear differences in growth parameters and biomass gain strategies among provenance when they are grown under similar conditions, and such differences could possibly be observed at an early developmental stage. Variability studies are the prerequisite for genetic improvement of any tree species. Selection of the best provenance of desired species for a given site or region is necessary for achieving maximum productivity in plantation forestry. But such information is lacking for M. officinalis. So, the main objective was to identify germplasm sources of $M$. officinalis that have a good seed germination capacity and seedling traits suitable for reforestation in the Fuyang city in China. A specific objective was to tentatively explore the adaptive strategy of $M$. officinalis populations in order to provide some orientation for the genetic management of this species. For this purpose, an attempt was made to evaluate the genetic diversity among and within M. officinalis provenances based on morphological differences in seed and seedling traits possibly linked to the establishment and end use of this species.

\section{Materials and methods}

\section{Seed resources and collection}

The present investigation was carried out to study the variation in seed germination in a nursery, and seedling parameters in selected provenances of $M$. officinalis. Fifteen provenance of $M$. officinalis mainly distribute mountains of Zhejiang, Fujian, Guangxi, Chongqing, Shanxi, Gansu, and Sichuan provinces. A total of 150 individuals of $M$. officinalis representing 15 distinct populations were sampled from its natural habitats (including Jingning, Qingyuan, Suichang, Zhenghe, Pucheng, Wuyishan, Longsheng, Kaixian, Xixiang, Chenggu, Ningqiang, Yanxian, Lueyang, Kangxian, and Baoxing). Seeds were harvested from each source to establish a provenance trial. Selected seed sources ranged from $26^{\circ} 05^{\prime} \mathrm{N}$ to $33^{\circ} 19^{\prime} \mathrm{N}$ latitude and $102^{\circ} 35^{\prime} \mathrm{E}$ to $119^{\circ} 38^{\prime} \mathrm{E}$ longitude and altitude from 336 to $1387 \mathrm{~m}$ (Fig. 1, Tab. 1).

For each site, $3 \mathrm{~kg}$ of seeds (approximately 1400 seeds per tree) were collected (October, 2008) from 10 candidate trees from natural stands, which were 50-100 m apart to avoid narrowing down the variation in sample due to relatedness or inbreeding (He, 2009; Zheng et al., 2009). The bulk sample from each site was given an accession number (provenance title) before bringing them to laboratory. Ripen cones of $M$. officinalis were allowed to dry in the sun for $24 \mathrm{~h}$. Thereafter, seeds were soaked in cold water overnight, macerated on a wire mesh and rinsed with water to remove the pulp. Seeds tended sink to the bottom while the soft pulp material tended to float. The seeds were dried in the sun for $24 \mathrm{~h}$. Moisture percentage in seed samples was determined on fresh weight basis by drying the seeds at $103 \pm 3^{\circ} \mathrm{C}$ for $24 \mathrm{~h}$.

\section{Characterization of seed size}

Morphological variability in seed characteristics (seed length, width, height, seed length/width ratio and seed weight) was evaluated. The shape of seeds (Vs) can be calculated by measuring length, width, and height of a seed and dividing all values by length, so that length is unity, and then calculating the variance of these three values by dividing the summed squared deviation from the mean by $n=3$ (Bedder et al., 1998). Five replicate samples, each consisting of 50 seeds, were randomly selected from each seed lot and their length, width and height were measured using a micrometer (Besto make). Seed weight of five rep-

Tab. 1. The natural condition of Magnolia officinalis in collect seed locus

\begin{tabular}{|c|c|c|c|c|c|c|c|}
\hline Provenances & $\begin{array}{l}\text { Latitude } \\
(\mathrm{N})\end{array}$ & $\begin{array}{l}\text { Longitude } \\
\text { (E) }\end{array}$ & $\begin{array}{l}\text { Altitude } \\
\text { (m) }\end{array}$ & $\begin{array}{l}\text { Average annual } \\
\text { temperature }\left({ }^{\circ} \mathrm{C}\right)\end{array}$ & $\begin{array}{l}\text { Average annual } \\
\text { sun exposure }(\mathrm{h})\end{array}$ & $\begin{array}{l}\text { Average annual } \\
\text { rainfall }(\mathrm{mm})\end{array}$ & $\begin{array}{c}\text { Frost-free } \\
\text { days }(\mathrm{d})\end{array}$ \\
\hline Jingning, Zhejiang & $119^{\circ} 38^{\prime}$ & $27^{\circ} 58^{\prime}$ & 653 & 17.6 & 1774 & 1542.7 & 241 \\
\hline Qingyuan, Zhejiang & $119^{\circ} 15^{\prime}$ & $27^{\circ} 45^{\prime}$ & 1266 & 17.4 & 2169 & 1760 & 245 \\
\hline Suichang, Zhejiang & $119^{\circ} 12^{\prime}$ & $28^{\circ} 21^{\prime}$ & 1038 & 16.8 & 1755 & 1510 & 251 \\
\hline Zhenghe, Fujian & $119^{\circ} 10^{\prime}$ & $27^{\circ} 24^{\prime}$ & 851 & 17.5 & 2800 & 1600 & 320 \\
\hline Pucheng, Fujian & $118^{\circ} 37^{\prime}$ & $28^{\circ} 03^{\prime}$ & 336 & 17.2 & 1894 & 1782.2 & 255 \\
\hline Wuyishan, Fujian & $118^{\circ} 01^{\prime}$ & $27^{\circ} 47^{\prime}$ & 1123 & 17.7 & 1884 & 1881 & 273 \\
\hline Longsheng, Guangxi & $110^{\circ} 04^{\prime}$ & $26^{\circ} 05^{\prime}$ & 1050 & 18.1 & 1408 & 1932 & 314 \\
\hline Kaixian, Chongqing & $106^{\circ} 17^{\prime}$ & $29^{\circ} 28^{\prime}$ & 635 & 13.5 & 1695 & 1153 & 237 \\
\hline Xixiang, Shanxi & $107^{\circ} 25^{\prime}$ & $32^{\circ} 54^{\prime}$ & 610 & 14.4 & 1624 & 923.5 & 253 \\
\hline Chenggu, Shanxi & $107^{\circ} 26^{\prime}$ & $33^{\circ} 03^{\prime}$ & 1136 & 14.1 & 1657 & 857 & 245 \\
\hline Ningqiang, Shanxi & $106^{\circ} 17^{\prime}$ & $32^{\circ} 49^{\prime}$ & 776 & 12.9 & 1570 & 1121 & 247 \\
\hline Yangxian, Shanxi & $107^{\circ} 30^{\prime}$ & $33^{\circ} 19^{\prime}$ & 1387 & 14.7 & 1544 & 935.3 & 201 \\
\hline Lueyang, Shanxi & $106^{\circ} 19^{\prime}$ & $33^{\circ} 16$ & 1372 & 13.2 & 1522 & 860 & 203 \\
\hline Kangxian, Gansu & $105^{\circ} 41^{\prime}$ & $33^{\circ} 03^{\prime}$ & 740 & 12.6 & 1434 & 742 & 207 \\
\hline Baoxing, Sichuan & $102^{\circ} 35^{\prime}$ & $30^{\circ} 34^{\prime}$ & 751 & 16.3 & 1125 & 1652 & 291 \\
\hline
\end{tabular}




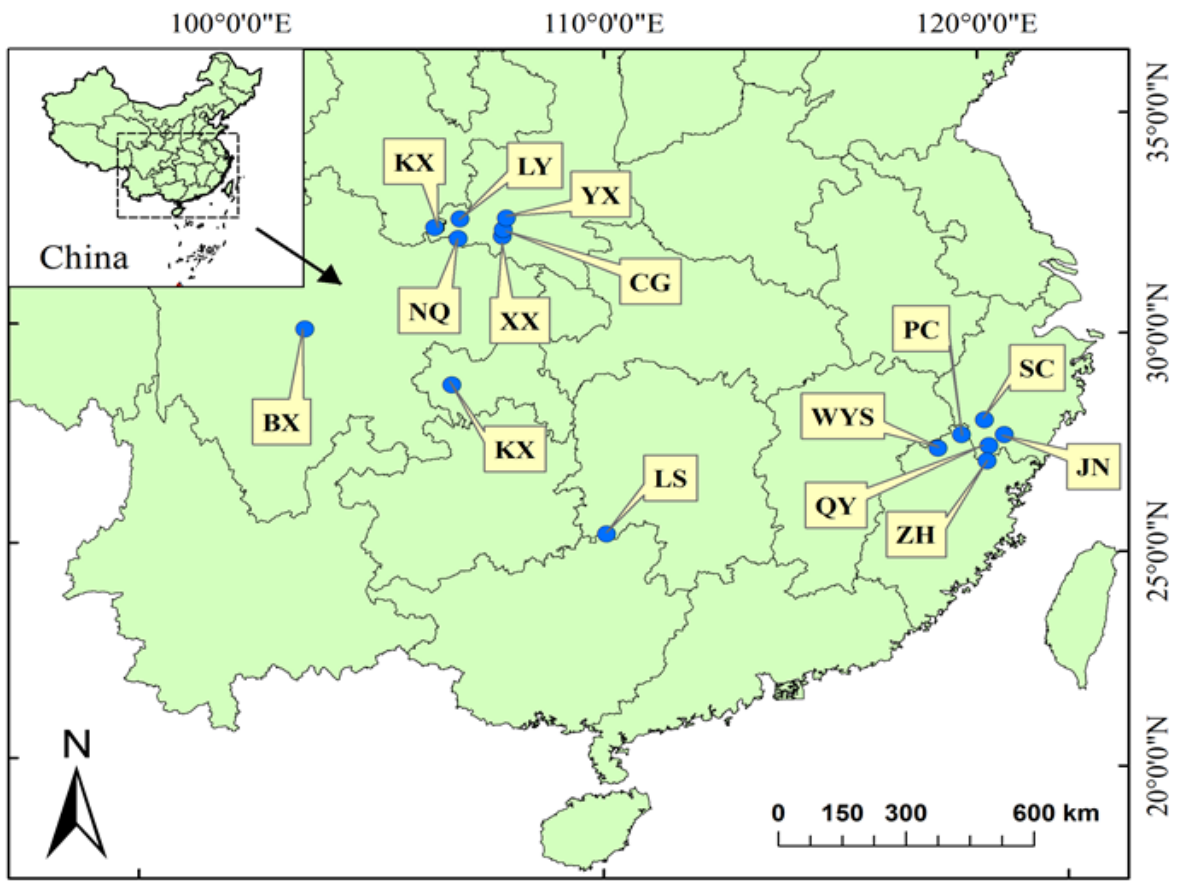

Fig. 1. Geographic distribution of 15 Magnolia officinalis provenances in China Notes: JN-Jingning, QY-Qingyuan, SC-Suichang, ZH-Zhenghe, PC-Pucheng, WYS-Wuyishan, LSLongsheng, KIX-Kaixian, XX-Xixiang, CG-Chenggu, NQ-Ningqiang, YX-Yangxian, LS-Longsheng, KX-Kangxian, BX-Baoxing.Similarly

licate samples (each of 100 seeds) were also obtained as per ISTA (International Seed Testing Association) regulations using electronic top pan balance. The seeds of each provenance were stored in seed containers of $5 \mathrm{~kg}$ capacity consisted of 18 gauge of GI (hot dip galvanized steel) sheets at room temperature and sowing was done in second week on November 2008.

\section{Germination tests and seedling traits}

The study was conducted between 2008 and 2009 . The research site is located near Fuyang town in the China (long. $29^{\circ} 44^{\prime} \mathrm{N}$, lat. $119^{\circ} 25^{\prime} \mathrm{E}$, alt. $361 \mathrm{~m}$ ). The climate is semi-wetness with a mean annual rainfall of $1452 \mathrm{~mm}$. The annual mean temperature is $16.27^{\circ} \mathrm{C}$. Seeds were surface sterilized with $0.3 \% \mathrm{KMnO}_{4}$ and soaked in distilled water for $24 \mathrm{~h}$ before sowing in $1 \times 1 \mathrm{~m}$ well prepared nursery beds (lines $20 \mathrm{~cm}$ apart and seeds in lines $5 \mathrm{~cm}$ apart, $1-5$ to $2.0 \mathrm{~cm}$ deep) in a randomized block design with three replicates (200 seeds per replicates). Seed germination was recorded for 40 days or until there was no further germination for a few days. The weeding and irrigation of beds were done manually for one year.

To assess the periodic growth, 10 seedlings of each provenance in each of the three replicates were randomly tagged; plant height and diameter were recorded. Measurements of number of leaves/plant $(N L / P)$, number of lateral root $(N L R)$, leaf area/plant $(L A / P)$, main root length $(M R L)$ were carried out at October 2009. Measurements of shoot height, collar diameter and dry weights of stem, leaf and root, were carried out at June, August and October 2009, respectively. Namely, there were three har- vests per provenance. Plants were divided into stem, leaf and root portions ( 5 seedlings of each provenance in each of the three replicates were randomly selected). All plant parts were oven-dried at $85^{\circ} \mathrm{C}$ to constant weight for determining the stem, leaf and root dry weights. The root to shoot ratio was calculated from the harvest data. The relative growth rate $(R G R)$ and the net assimilation rate $N A R$ were calculated as $R G R=\left(\ln W_{2}-\ln W_{1}\right) /\left(t_{2}-t_{1}\right) N A R=[($ $\left.\left.W_{2}-W_{1}\right)\left(\ln L_{2}-\ln L_{1}\right)\right] / t\left(L_{2}-L_{1}\right)$, where $W_{1}, L_{1}$ and $W_{2}$, $L_{2}$ are seedling dry weights and leaf area/plant $(L A / P)$ at times $t_{1}$ and $t_{2}$ (Hoffmann and Poorter, 2002; Khurana and Singh, 2004a) where $t_{2}-t_{1}$ was 60 days. Heritability $\left(H^{2}\right)$ was calculated in accordance with Zhang et al. (2009).

\section{Statistical analysis}

An analysis of variance was performed using the general linear model (GLM) procedure of the statistical software SPSS version (10) for windows. Inc. Chicago, USA, and a regression analysis were done using the JMP 3.2 statistical package. Tukey's HSD test (Steel and Torrie, 1980) was performed to determine possible differences between means $(p \leq 0.05)$. Design of experiment was arranged based on randomized complete block designs (RCBD)

\section{Results}

\section{Morphological variation in seed characters}

There were significant differences $(p \leq 0.01)$ among provenances in seed length, width, height, seed length/ width ratio, seed weight and $\mathrm{Vs}$, and coefficient of variation were $5.85,5.74,6.58,7.2,17.54$ and $11.16 \%$, respectively. 
On average, seed length ranged from $8.84 \pm 0.87$ (Yangxian) to $10.78 \pm 0.72 \mathrm{~mm}$ (Baoxing) among provenances $($ mean $=9.58 \mathrm{~mm})$. Mean seed width was maximum in Qingyuan locations followed by Suichang. Chenggu was recorded lowest mean seed width as compared to the other provenances, seed width ranged from $7.25 \pm 0.70$ to $8.68 \pm 0.83 \mathrm{~mm}$. Seed weight was smaller in north-west population (including Kaixian, Xixiang, Chenggu, Ningqiang, Yangxian, Lueyang, Kangxian, and Baoxing) than in south-east population (including Jingning, Qingyuan, Suichang, Zhenghe, Pucheng, Wuyishan and Longsheng). Yangxian and Wuyishan were recorded lowest Vs values as compared to the other provenances, Vs values ranged from 0.042 to 0.062 . Average seed moisture was recorded highest $(12.37 \pm 0.95 \%)$ form Lueyang population, followed by Suichang $(12.36 \pm 0.90 \%)$ and Yangxian is minimum $(9.42 \pm 0.09 \%)$. There was $1.22,1.20,1.26,1.24,1.76$ and 1.48-fold variation between highest and lowest values of seed length, width, height, seed length/ width ratio, seed weight and Vs values, respectively (Tab. 2).

\section{Seed germination}

There were significant differences $(p \leq 0.01)$ among provenances in seed germination percentage. Seed germination percentage was maximum for Ningqiang locations followed by Chenggu and was lowest in Kaixian, overall seed germination in nursery averaged $59.4 \%$ varying from $26.6 \%$ to $91.2 \%$. There were high germination potential form Jingning, Wuyishan and Longsheng locations. On average, seedlots from Qingyuan, Zhenghe, Pucheng, Kaixian, Longsheng and Kangxian had 26.6-49.9 \% germination, whereas, the rest had germination percentages of $52.2-91.2 \%$ (Fig. 2).

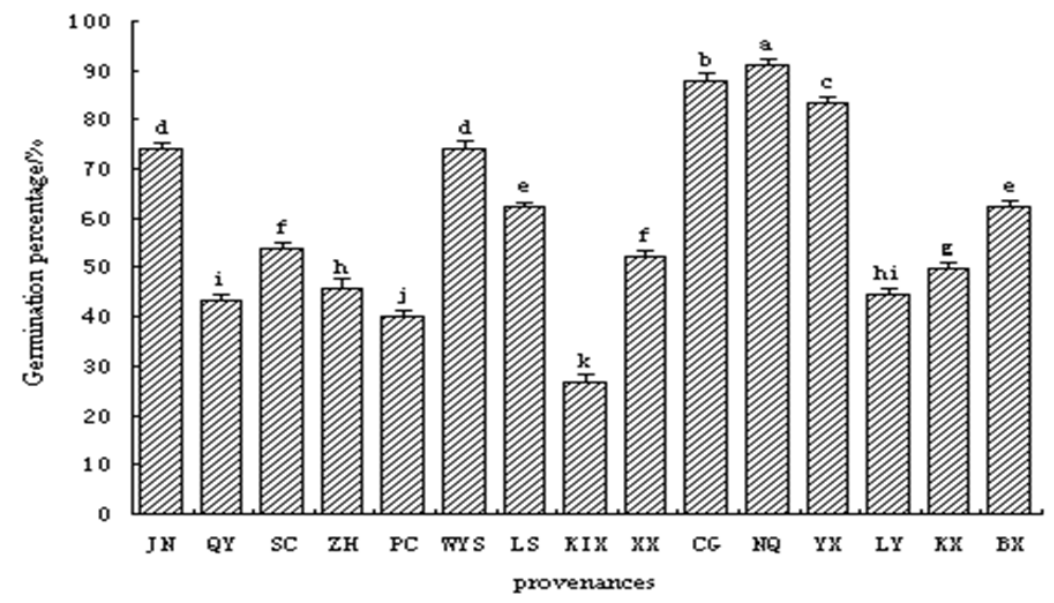

Fig. 2. The seeds germination percentage of M.officinalis from different provenances (Different letters indicate significant differences between provenances at $p \leq 0.05$ )

Tab. 2. Variation of Seeds morphology of Magnolia officinalis from different provenances $(\bar{X} \pm S D)$

\begin{tabular}{|c|c|c|c|c|c|c|}
\hline Provenances & $\begin{array}{l}\text { Seed length } \\
(\mathrm{mm})\end{array}$ & $\begin{array}{l}\text { Seed width } \\
(\mathrm{mm})\end{array}$ & $\begin{array}{l}\text { Seed height } \\
(\mathrm{mm})\end{array}$ & $\begin{array}{l}\text { Seed length/ } \\
\text { width ratio }\end{array}$ & $\begin{array}{c}\text { 100-seed weight } \\
(\mathrm{g})\end{array}$ & Vs \\
\hline Jingning & $9.73 \pm 0.63 \mathrm{bc}$ & $8.11 \pm 0.82 \mathrm{~cd}$ & $4.66 \pm 0.49 \mathrm{abc}$ & $1.21 \pm 0.15 \mathrm{cde}$ & $17.57 \pm 0.43 c$ & 0.047 \\
\hline Qingyuan & $9.53 \pm 0.63 \mathrm{~cd}$ & $8.68 \pm 0.83 a$ & $4.25 \pm 0.32 \mathrm{hi}$ & $1.11 \pm 0.13 f$ & $16.10 \pm 0.34 \mathrm{~d}$ & 0.059 \\
\hline Suichang & $9.16 \pm 0.54 \mathrm{e}$ & $8.56 \pm 1.06 \mathrm{ab}$ & $4.35 \pm 0.35 \mathrm{fgh}$ & $1.09 \pm 0.19 \mathrm{f}$ & $16.80 \pm 0.64 \mathrm{~cd}$ & 0.055 \\
\hline Zhenghe & $9.28 \pm 0.86 \mathrm{de}$ & $8.26 \pm 0.90 \mathrm{bc}$ & $4.42 \pm 0.30 \mathrm{efg}$ & $1.14 \pm 0.18 \mathrm{ef}$ & $16.94 \pm 0.63 \mathrm{~cd}$ & 0.051 \\
\hline Pucheng & $9.95 \pm 1.13 \mathrm{~b}$ & $8.00 \pm 1.11 \mathrm{cde}$ & $4.76 \pm 0.40 \mathrm{a}$ & $1.28 \pm 0.30 \mathrm{abcd}$ & $17.40 \pm 1.06 \mathrm{c}$ & 0.046 \\
\hline Wuyishan & $9.29 \pm 0.68 \mathrm{de}$ & $7.85 \pm 0.97 \mathrm{def}$ & $4.73 \pm 0.41 \mathrm{ab}$ & $1.20 \pm 0.19 \mathrm{de}$ & $17.75 \pm 0.87 \mathrm{bc}$ & 0.042 \\
\hline Longsheng & $10.70 \pm 0.70 \mathrm{a}$ & $8.33 \pm 0.83 a b c$ & $4.60 \pm 0.32 \mathrm{abcd}$ & $1.30 \pm 0.17 \mathrm{ab}$ & $20.37 \pm 0.37 \mathrm{a}$ & 0.055 \\
\hline Kaixian & $9.96 \pm 0.92 b$ & $8.36 \pm 1.03 \mathrm{abc}$ & $4.59 \pm 0.60 \mathrm{bcd}$ & $1.21 \pm 0.16 \mathrm{cde}$ & $16.95 \pm 0.81 \mathrm{~cd}$ & 0.051 \\
\hline Xixiang & $9.22 \pm 0.65 \mathrm{e}$ & $8.01 \pm 0.78 \mathrm{cde}$ & $4.30 \pm 0.35 \mathrm{ghi}$ & $1.16 \pm 0.17 \mathrm{ef}$ & $16.21 \pm 0.33 \mathrm{~d}$ & 0.052 \\
\hline Chenggu & $9.19 \pm 0.69 \mathrm{e}$ & $7.25 \pm 0.70 \mathrm{~g}$ & $3.90 \pm 0.31 \mathrm{j}$ & $1.28 \pm 0.17 \mathrm{abc}$ & $12.12 \pm 0.50 \mathrm{f}$ & 0.057 \\
\hline Ningqiang & $9.41 \pm 0.66 \mathrm{de}$ & $7.54 \pm 0.92 \mathrm{fg}$ & $4.16 \pm 0.25 \mathrm{i}$ & $1.27 \pm 0.19 \mathrm{bcd}$ & $14.47 \pm 0.14 \mathrm{e}$ & 0.053 \\
\hline Yangxian & $8.84 \pm 0.87 f$ & $7.74 \pm 0.92 \mathrm{ef}$ & $4.55 \pm 0.51 \mathrm{cde}$ & $1.15 \pm 0.15 \mathrm{ef}$ & $11.55 \pm 0.23 \mathrm{f}$ & 0.042 \\
\hline Longsheng & $9.46 \pm 0.89 \mathrm{cde}$ & $7.37 \pm 1.18 \mathrm{~g}$ & $3.77 \pm 0.62 j$ & $1.33 \pm 0.29 \mathrm{ab}$ & $11.57 \pm 0.64 f$ & 0.062 \\
\hline Kangxian & $9.17 \pm 0.66 \mathrm{e}$ & $7.25 \pm 0.70 \mathrm{~g}$ & $3.90 \pm 0.31 \mathrm{j}$ & $1.28 \pm 0.17 \mathrm{abcd}$ & $12.11 \pm 0.46 f$ & 0.056 \\
\hline Baoxing & $10.78 \pm 0.72 a$ & $8.13 \pm 1.09 \mathrm{~cd}$ & $4.49 \pm 0.48 \mathrm{def}$ & $1.35 \pm 0.21 \mathrm{a}$ & $18.62 \pm 0.66 \mathrm{~b}$ & 0.057 \\
\hline Mean & 9.58 & 7.62 & 4.36 & 1.22 & 15.77 & 0.052 \\
\hline CV (\%) & 5.85 & 5.74 & 7.2 & 6.58 & 17.54 & 11.16 \\
\hline
\end{tabular}

Notes: Within each provenance, values marked by the same letter are not significantly $(p \leq 0.05)$ different 
278

Correlation analysis for seed traits

Seed traits were inter-correlated (Tab. 3). The 100seed weight showed a higher positive correlation with seed width than with seed length $(r=0.74$ and 0.70 , respectively). The seed length/width ratio was positively correlated with seed length $(r=0.56, p \leq 0.05)$.There were significant negative correlation $(r=-0.56, p \leq 0.05)$ between seed length/width ratio and seed width. The 100seed weight was positively correlated with seed height $(r$ $=0.74, p \leq 0.01)$.

Tab. 3. Mean correlation coefficients $(r)$ between seed variables of Magnolia officinalis provenances

\begin{tabular}{cccccc}
\hline Variables & $\begin{array}{c}\text { Seed } \\
\text { length }\end{array}$ & $\begin{array}{c}\text { Seed } \\
\text { width }\end{array}$ & $\begin{array}{c}\text { Seed } \\
\text { height }\end{array}$ & $\begin{array}{c}\text { Seed length/ } \\
\text { width ratio }\end{array}$ & $\begin{array}{c}\text { 100-seed } \\
\text { weight }\end{array}$ \\
\hline $\begin{array}{c}\text { Seed length } \\
1\end{array}$ & & & & \\
$\begin{array}{c}\text { Seed width } \\
0.37\end{array}$ & 1 & & & \\
$\begin{array}{c}\text { Seed height } \\
0.38\end{array}$ & $0.60^{*}$ & 1 & & \\
$\begin{array}{c}\text { Seed length/ } \\
\text { width ratio }\end{array}$ & $0.56^{*}$ & $-0.56^{*}$ & -0.22 & 1 & \\
$\begin{array}{c}100 \text {-seed } \\
\text { weight }\end{array}$ & $0.70^{* *}$ & $0.74^{* *}$ & $0.74^{* *}$ & -0.061 & 1 \\
\hline
\end{tabular}

Notes: ${ }^{* * *}$ stand for the significances at the 0.05 and 0.01 levels

The correlation coefficient between geography, climate and seed trait

Correlation analysis between seeds characters and geographical climatic factors showed that: seed length was significantly positively correlated with average annual rainfall or frost-free days. Seed width had a positive and significant correlation with longitude, frost-free days of provenance. Seed width and seed weight while it showed positive and significant correlation with average annual temperature and average annual rainfall. There were significant inverse correlation, seed width and seed weight of $M$. officinalis from different provenances with latitude of seed source. There was significant positive correlation between seed height and average annual rainfall or average annual temperature (Tab. 4).

\section{Genetic variation in seedling traits}

There were significant differences $(p \leq 0.001, p \leq 0.001$, $p \leq 0.05, p \leq 0.001$ and $p \leq 0.001)$ existed among provenances in shoot height, collar diameter, number of leaves/plant, main root length and number of lateral root (Fig. 3A, B,
C, D, and E). Provenance Longsheng indicated the greatest shoot height, followed by provenance Yangxian, while provenance Kangxian ranked lowest and other provenances remained intermediate. Collar diameter was considerably higher for Yangxian compared to other provenances. Seedling height and collar diameter had high heritability among provenances $\left(H^{2}=0.93\right.$ and 0.73 , respectively). The effect of sampling date was significant $(p \leq 0.001)$ on shoot height and collar diameter (Fig. 5A, B). At October seedling, Leavers number was highest to Longsheng and least to Kaixian. The provenance Wuyishan showed a higher main root length. The provenance Chenggu and Yangxian showed a higher number of lateral roots.

\section{Root, stem and leaf dry weights}

Seedling root dry weight showed significant variation among the provenances. Provenance Ningqiang indicated the greatest root dry weight, followed by provenance Wuyishan, while provenance Kangxian ranked lowest. Root dry weight of Ningqiang is 3 times more than that of Kangxian. There were significant differences $(p \leq 0.001, p \leq 0.001)$ existed among provenances in stem dry weight and leaf dry weight. (Fig. 3F, G, H). Provenance Longsheng indicated the greatest stem dry weight and leaf dry weight, while provenance Kangxian ranked lowest in stem dry weight. The effect of sampling date was significant $(p \leq 0.001)$ on root, stem and leaf dry weights (Fig. 5C, D, F).

\section{Root/shoot ratio and total dry weight}

Differences in root to shoot ratio and total dry weight among provenances were significant $(F=4.079, p \leq 0.001$; $F=5.615, p \leq 0.001)$.The Provenance Baoxing showed a higher root/shoot ratio compared to the provenance and the lowest one was found in Longsheng, total dry weight was highest to Wuyishan and least to Kangxian (Fig. 4). The effect of sampling date was significant $(p \leq 0.05)$ on seedling height, ground diameter, root dry weight, stem dry weight and leaf dry weight (Fig. 5).

\section{The relative growth rate and the net assimilation rate}

No significant differences $(F=1.953, F=1.773)$ existed among provenances in the relative growth rate $(R G R)$ and the net assimilation rate $(N A R)$, although the north-west population indicated, on average slightly higher values to south-east population. Provenance Jingning indicated the Tab. 4. The correlation coefficient between geographic, climate and seed trait of Magnolia officinalis

\begin{tabular}{|c|c|c|c|c|c|}
\hline Item & Seed length & Seed width & Seed height & Seed length/width ratio & 100-seed weight \\
\hline Longitude & -0.16 & $0.54^{*}$ & 0.44 & $-0.60^{*}$ & 0.4 \\
\hline Latitude & -0.45 & $-0.78^{* *}$ & $-0.68^{* *}$ & 0.3 & $-0.84^{* *}$ \\
\hline Altitude & -0.33 & -0.12 & -0.36 & -0.18 & -0.42 \\
\hline Average annual temperature & 0.35 & $0.68^{* *}$ & $0.68^{* *}$ & -0.3 & $0.75^{* *}$ \\
\hline Average annual sun exposure & -0.35 & 0.37 & 0.17 & $-0.62^{*}$ & 0.13 \\
\hline Average annual rainfall & $0.55^{*}$ & $0.70^{* *}$ & $0.71^{* *}$ & -0.13 & $0.85^{* *}$ \\
\hline Frost-free days & $0.53^{*}$ & $0.50^{*}$ & 0.45 & 0.01 & $0.79^{* *}$ \\
\hline
\end{tabular}

Notes: ${ }^{*}{ }^{* *}$ stand for the significances at the 0.05 and 0.01 levels 

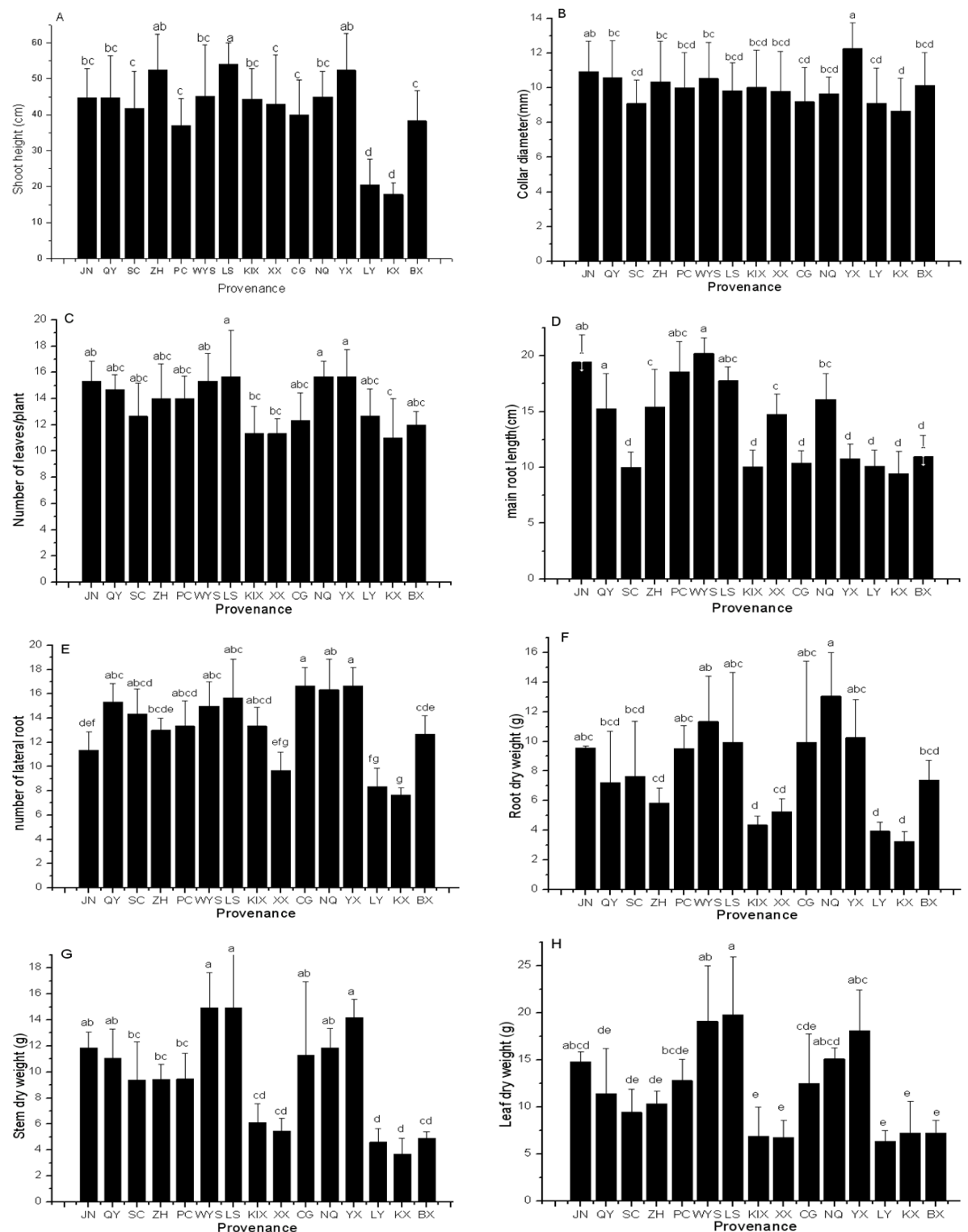

Fig. 3. Seedling growth characteristics in fifteen M.officinalis provenances in the nursery at October seedling. (A) height, (B) Collar diamenter, (C) number of leaves, (D) main root length, (E) number of lateral root, (F) root dry weight, (G)stem dry weight, and (H) Leaf dry weight. Bars indicate standard error of the mean. Different letters indicate significant differences between provenances at $p \leq 0.05$

greatest $R G R$, followed by provenance Kangxian, while provenance Zhenghe ranked lowest and other provenances remained intermediate, $N A R$ was similar for $R G R$ in result. (Tab. 5)

The correlation coefficient between geography, climate and seedling growth traits

Correlation analyses revealed that shoot height had a positive correlation with longitude of $\operatorname{seed} \operatorname{origin}(r=$ 0.34 ), albeit not statistically significant. Shoot height had a significant positive correlation with the average annual temperature and frost-free days $(r=0.55, p \leq 0.05 ; r=0.56$, $P \leq 0.05$, respectively), and negative correlation with latitude of the seed origin $(r=0.51, p \leq 0.05)$ (Tab. 6). Stem dry weight was significantly positively correlated with average annual temperature $(r=0.53, p \leq 0.05)$ (Tab. 6).

\section{Discussion}

Phenotypic variation is determined by genotype and environment interactions and is assumed to be the expression of genotypic variation when environmental conditions are controlled (Li et al., 2009, Westoby et al., 2002). This study of provenance variation in $M$. officinalis has found variation in seed size, shape and weight, in germination percentages and in growth characteristics (seedling height, ground diameter, number of leaves/plant, number of lateral root, leaf area/plant, main root length). Thompson, 


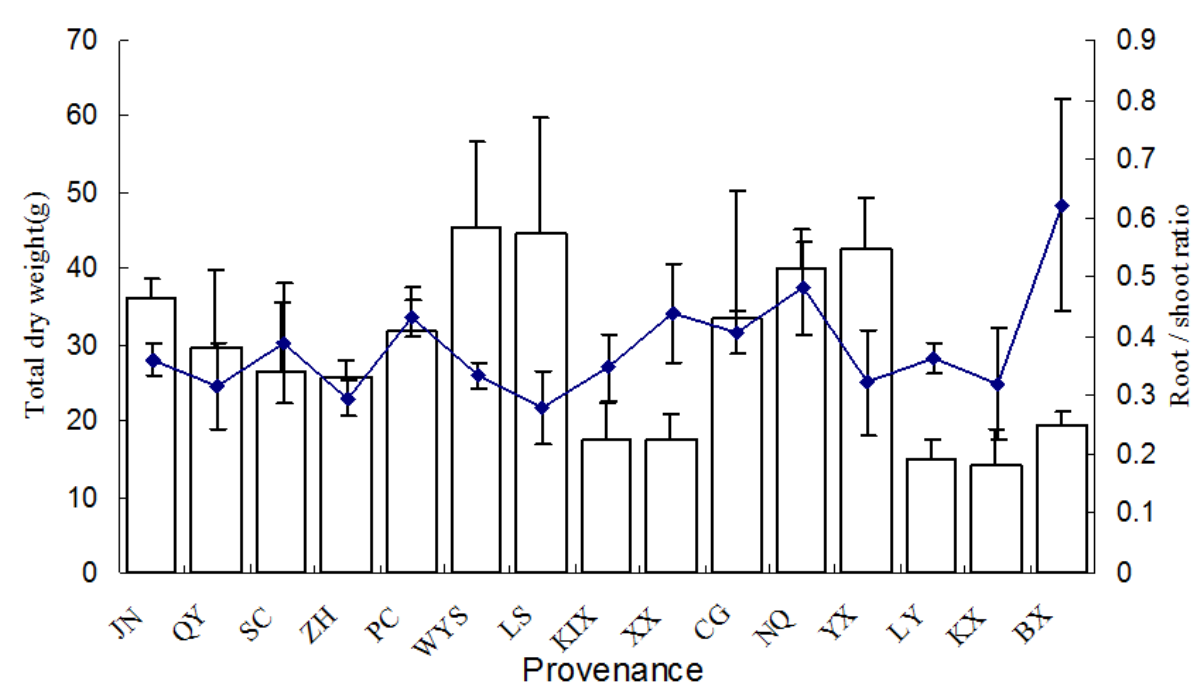

Fig. 4. Root to shoot ratio and total dry weight of at October seedlings in fifteen M.officinalis provenances. Bars indicate standard error of the mean. Different letters indicate significant differences between provenances at $p \leq 0.05$
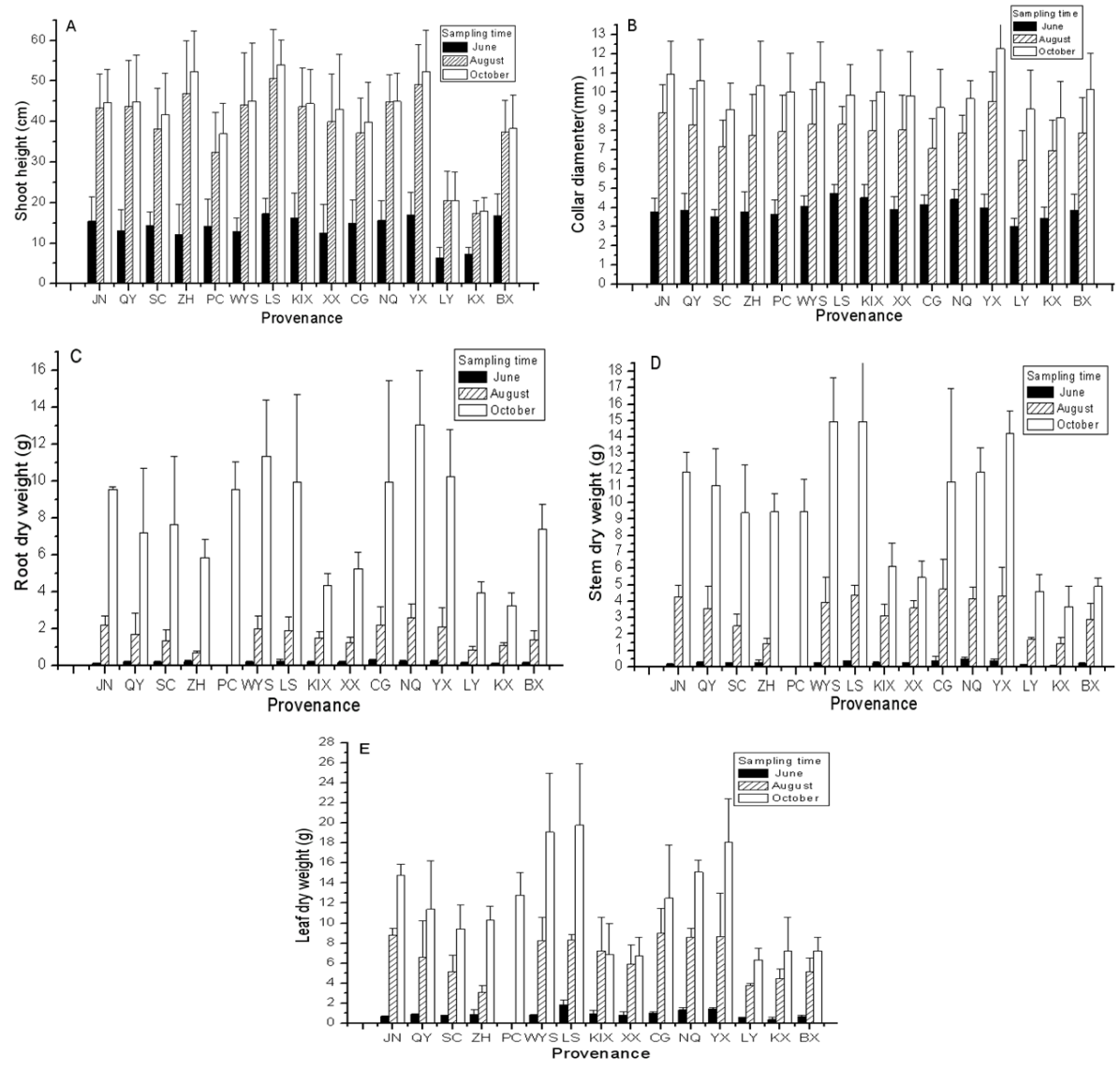

Fig. 5. Effect of sampling time on seedling growth characteristics in the nursery . (A) shoot height, (B) Collar diamenter, (C) root dry weight,(D)stem dry weight,(F)leaf dry weight. Bars indicate standard error of the mean

Band and Hodgson (1993) showed that among 97 species of the british flora, seeds which are persistent in the soil tended to be small and compactly shaped, while seeds that are transient in the soil were larger, flattened or elongate. Our result indicates that Yangxian seed are persistent in the soil. It is possible that the variation in morphological characters among provenances is due to resource availability at the time of fruiting and so to seed size. This in turn could be due to different environments at the geographic origins of each seed and seasonal variables (Murali, 1997). Loha et al. (2009) also observed significant variation in seed size traits of Cordia Africana. 
Tab. 5. The relative growth rate and the net assimilation rate of Magnolia officinalis seedlings from different provenances $(\bar{X}$ $\pm S D)$

\begin{tabular}{ccc}
\hline Provenances & RGR $\left(\mathrm{mg} \cdot \mathrm{g}^{-1} \cdot \mathrm{d}^{-1}\right)$ & $\mathrm{NAR}\left(\mathrm{g} \cdot \mathrm{m}^{-2} \cdot \mathrm{d}^{-1}\right)$ \\
\hline Jingning & $0.0454 \pm 0.0029$ & $3.3407 \pm 0.3388$ \\
Qingyuan & $0.0352 \pm 0.0080$ & $2.6665 \pm 0.6028$ \\
Suichang & $0.0331 \pm 0.0052$ & $2.3646 \pm 0.5821$ \\
Zhenghe & $0.0237 \pm 0.0099$ & $1.6594 \pm 0.8182$ \\
\hline Pucheng & $0.0391 \pm 0.0056$ & $3.0296 \pm 0.7183$ \\
\hline Wuyishan & $0.0297 \pm 0.0022$ & $1.8152 \pm 0.1521$ \\
\hline Longsheng & $0.0358 \pm 0.0122$ & $2.5561 \pm 1.1497$ \\
Kaixian & $0.0365 \pm 0.0063$ & $2.756 \pm 0.5021$ \\
Xixiang & $0.0374 \pm 0.0010$ & $3.3177 \pm 0.7607$ \\
Chenggu & $0.0337 \pm 0.0029$ & $2.5812 \pm 0.2662$ \\
\hline Ningqiang & $0.0320 \pm 0.0085$ & $2.2958 \pm 0.7263$ \\
\hline Yangxian & $0.0342 \pm 0.0053$ & $2.4315 \pm 0.1735$ \\
Longsheng & $0.0419 \pm 0.0083$ & $2.9216 \pm 0.7212$ \\
Kangxian & $0.0365 \pm 0.0021$ & $2.6083 \pm 0.384$ \\
F & 1.953 & 1.7730 \\
\hline
\end{tabular}

In the present study, there were significant differences among provenances in seed germination percentage, varying from $26.6 \%$ to $91.2 \%$ (Fig. 2). A marked intraspecific variability in the germination ability have also been reported in pine species (Lopez-Upton, 2005).Causes of such variability might be generally attributed either to (a) genetic characters of source population/plant (Bewley and Black, 1994), or (b) impact of mother plant environment (Gutterman, 1992). There was a strong intercharacter correlation, particularly between seed weight and seed width (Tab. 3). Correlated quantitative traits are of a major interest in an improvement program, as the improvement of one character may cause simultaneous changes in the other character. Similar results have been reported for Faidherbia albida (Dangasuk et al., 1997).In addition, morphometric traits especially seed weight, showed a strong correlation with latitude $(r=-0.84, p \leq 0.01)$ and mean annual temperature $(r=0.75, p \leq 0.05)$ of seed origin (Tab. $4)$. This indicates that seed size is not only heritable but also strongly affected by environmental variations. While it is a well-known fact that latitude and temperature has an inverse relationship, which is consistent with the present finding. Correlation analysis between seed characters and geographical climatic factors showed that the main variation was of geographical locations. The annual mean temperature, annual precipitation and frost-free period were the leading ecological factors restricting the seed variation.

Large differences in seedling height and collar diameter were found among provenances, and as much as 0.93 of the total variation was due to provenance effect. This indicates that there is adequate genetic variability for seedling height growth in the present material. Similar results have been reported for broadleaved species (Cundall et al., 2003).This also indicates that seedling height could be employed as a proxy indicator for early selection of provenances for further testing. Base on seedling height values and seed germination percentage for fifteen provenances tested, Longsheng, Yangxian, Jingning, Wuyishan, Kaixian and Ningqiang provenance have been identified suitable to produce quality seedlings of $M$. officinalis.

In the present study, there were significant differences among provenances in leaf number, main root length, number of lateral root and root/shoot ratio. A similar result was reported for Faidherbia albida (Dangasuk et al., 1997). This also suggests that the root/shoot ratio in seedlings alone indicates adaptation to water stress. Rehfildt and Wycoff (1981) reported that the Pinus seedlings raised from different provenance often display different pattern of root, stem and leaf growth as observed in this study also. These variations in growth characteristics of different Dalbergia sissoo provenance may be attributed to adaptation because the seedlings from all the sources were raised under identical conditions (Singh and Pokhriyal, 2000). Leaf number and leaf dry weight/plant varied significantly among provenance of $M$. officinalis. Similar observations have also been documented to leaf biomass of Acacia mangium and Celtis australis (Salazar, 1989; Singh, 2006).

Relative growth rates $(R G R)$ values differ widely among plant species (e.g. between Brizamedia L. and Festuca ovina L.), and these differences can be related, to environmental conditions and to inherent species characteristics (Poorter and Remkes, 1990). In our study, provenances showed no statistically significant variation in the $R G R$. The variation in $R G R$ in woody species is generally assumed to be related to the variation in leaf area ratio $(L A R)$ and to be greater in deciduous species compared to evergreens (Antunez et al., 2001). Physiological mechanisms (Walter et Tab. 6. The correlation coefficient between geographic, climate and seedling growth traits of Magnolia officinalis

\begin{tabular}{ccccccccc}
\hline Item & Longitude & Latitude & Altitude & $\begin{array}{c}\text { Average annual } \\
\text { temperature }\end{array}$ & $\begin{array}{c}\text { Average annual } \\
\text { sun exposure }\end{array}$ & $\begin{array}{c}\text { Average annual } \\
\text { rainfall }\end{array}$ & $\begin{array}{c}\text { Frost-free } \\
\text { days }\end{array}$ \\
\hline Height & 0.34 & $-0.51^{*}$ & 0.06 & $0.55^{*}$ & 0.35 & 0.2 & 0.49 & $0.56^{*}$ \\
Collar diameter & 0.24 & -0.22 & 0.19 & 0.39 & -0.05 & 0.28 & 0.02 \\
Root dry weight & 0.22 & -0.19 & 0.09 & 0.33 & 0.22 & 0.47 & 0.22 \\
Stem dry weight & 0.45 & -0.42 & 0.35 & $0.53^{*}$ & 0.05 & 0.44 & 0.27 \\
Leaf dry weight & 0.31 & -0.35 & 0.27 & 0.46 & 0.08 & 0.45 & 0.25 \\
\hline Total dry weight & 0.35 & -0.35 & 0.26 & 0.47 & & & 0.23 \\
\hline
\end{tabular}

Notes: ${ }^{*}{ }^{* *}$ stand for the significances at the 0.05 and 0.01 levels 
282

al., 1993), leaf morphology (Poorter and Remkes, 1990) can be responsible for variation in the $R G R$. Our results suggest some variation in the $R G R$ associated with variation in NAR.

Correlation was found between seedling height and latitude of seed origin $(r=-0.51, p \leq 0.05)$. Such correlation is expected from a population of trees which is known to have naturally regenerated without human interference since primary colonization. The stands from which seeds were collected for the present study were remaining relict natural forests. The results are in disagreement with those obtained in early vigor (e.g. Kleinschmit et al., 1996). Seedling height decreased gradually from south to north geographically, while shoot diameter declines from east to west. That means the geographic variation of the plant at the seedling stage manifests a two-way variation with the latitude and longitude, but the variation is more significant with the former. Shoot height had a significant positive correlation with the average annual temperature.

The practical importance of the study is that heavier seedlings raised through suitable provenances may provide fair success in survival and growth of seedlings during outplanting as quality seedlings will only be able to withstand the adverse climatic conditions. However, further research should look into responses of genotypes $\times$ environment interaction in $M$. officinalis at different test sites over a wider range of environmental conditions within.

\section{Acknowledgements}

This research was supported by the Ministry of Science and Technology in China (200704022), Natural Science Foundation Key Project of Zhejiang Province (z3100041) and the National Natural Science Foundation of China (31270585).

\section{References}

Antunez I, Retamosa EC, Villar R (2001). Relative growth rate in phylogenetically related deciduous and evergreen woody species. Oecologia 128:172-180.

Bedder RM, Bakker JP, Grandin U, Kalamees R, Milberg P, Poschlod P, Thompson K, Willems JH (1998). Seed size, shape and vertical distribution in the soil: indicator of seed longevity. Funct Ecol 12:834-842

Bewley JD, Black M(1994). Seeds: Physiology of Development and Germination. Plenum Perse, New York, 211 p.

Bischoff A, Vonlanthen B, Steinger T (2006). Seed provenance matters - Effects on germination of four plant species used for ecological restoration. Basic App Ecol 7:347-359.

Cony MA, Trione SO (1998). Inter-and intraspecific variability in Prosopis flexuosa and P. chilensis: seed germination under salt and moisture stress. J Arid Environ 40:307-317.

Cruz A, Perez B, Velasco A, Moreno JM (2003). Variability in seed germination at the interpopulation and intraindividual levels of shrub Erica australis in response to fire-related cues.
Plant Ecol 169:93-103.

Cundall EP, Cahalan CM, Connolly T (2003). Early results of ash (Fraxinus excelsior L.) provenance trials at sites in England and Wales. Forestry 76:385-399.

Dangasuk OG, Seurei P, Gudu S (1997). Genetic variation in seed and seedling traits in 12 African provenances of Faidherbia albida (Del.) A. Chev. at Lodwar, Kenya. Agroforest Syst 37:133-141.

Fu LK (1992). China plant red data book- rare and endangered plants. Sci Press, Beijing, 416-417 p.

Giménez-Benavides L, Escudero A, Pérez-García F (2005). Seed germination of high mountain Mediterranean species: altitudinal, interpopulation and interannual variability. Ecol Res 20:433-444.

Gutterman Y (1992). Maternal effects on seed during development, 27-59 p. In: Fenner M (Ed.). Seeds. The Ecology of Regeneration in Plant Communities, Wallingford CAB Int.

Hamann A, Koshy MP, Namkoong G, Ying CC (2000). Genotype $\times$ environment interactions in Alnus rubra: developing seed zones and seed-transfer guidelines with spatial statistics and GIS. Forest Ecol Manag 136:107-119.

Hancock JF (2004). Plant evolution and the origin of crop species.CABI Publishing, Cambrige, MA.

He JS, Chen L, Si Y (2009). Population structure and genetic diversity distribution in wild and cultivated populations of the traditional Chinese medicinal plant Magnolia officinalis subsp. biloba (Magnoliaceae). Genetica 135:233-243.

Hoffmann WA, Poorter H (2002). Avoiding bias in calculations of relative growth rate. Ann Bot 80:37-42.

Hufford KM, Mazer SJ (2003). Plant ecotypes: genetic differentiation in the age of ecological restoration. Trends in Ecol and Evol 18:147-155.

Khurana E, Singh JS (2004 a). Response of five tropical tree seedlings to elevated $\mathrm{CO}_{2}$ of seed size and successional status. New Forests 27:139-157.

Kleinschmit J, Svolba V, Enescu A, Franke H, Rau M, Ruetz W (1996). First results of the provenance test with Fraxinus excelsior established. Forstarchiv 67:114-122.

Loha A, Tigabu M, Fries A (2009). Genetic variation among and within populations of Cordia africana in seed size and germination responses to constant temperatures. Euphytica 165:189-196.

Lopez-Upton J, Donahue JK, Plascencia-Escalante FO (2005). Provenance variation in growth characters of four subtropical pine species planted in Mexico. New Forests 29:1-13.

Marova IM, Ivanitskii VV, Veprintseva OD (2010). Individual ,population and geographic differentiation in advertising song of the Blyth's reed warbler, Acrocephalus dumetorum (Sylvidae). Biol Bull 37:846-860.

Meskel EW, Sinclair FL (2000). Growth variability in Senegalese provenance of Acacia nilotica spp. tomentosa. Agrofor Syst 48:207-213. 
Miller AJ, Schaal BA (2006). Domestication and the distribution of genetic variation in wild and cultivated populations of the Mesoamerican fruit tree Spondias purpurea L. (Anacardiaceae). Mol Ecol 15:1467-1480.

Murali KS (1997). Patterns of seed size, germination and seed viability of tropical tree species in Southern India. Biotropica 29:271-279.

Pan XP, Huang XG, Ren QY (1994). Study on seedling raising of Magnolia officinalis. J Chin Med Mater 19:147-149.

Poorter H, Remkes C (1990). Leaf area ratio and assimilation rate of 24 wild species differing in relative growth rate. Oecologia 83:553-559.

Rehfildt GE, WycoffWR(1981). Periodicity in shoot elongation among populations of Pinus contarta from the northern Rocky Mountains. Ann Bot 48:371-377.

Rosenthal JP, Kotanen PM (1994). Terrestrial plant tolerance to herbivory. Tree 9:145-149.

Salazar R (1989). Genetic variation of 16 provenances of Acacia mangium at nursery level in Turrialba Costa Rica. Comm For Rev 68:263-272.

Shu X, Yang ZL, Duan HP (2010). Seed germinating characteristics of the endangered plant Magnolia officinalis. Chin J Chin Materia Meduca 35:419-422.

Singh B, Bhatt BP, Prasad P (2006). Variation in seed and seedling traits of Celtis australis, a multipurpose tree, in Central Himalaya, India. Agroforest Syst 67:115-122.

Singh N, Pokhriyal TC (2000). Biomass distribution patternin relation to seed source variation in Dalbergia sissoo seedlings.
Ann For 8:238-249.

Steel RGD, Torrie JH (1980). Principles and procedures of statistics, $2^{\text {nd }}$ edn. McGraw-Hill, New York.

Thompson K, Band SR, Hodgson JG (1993). Seed size and shape predict persistence in soil. Funct Ecol 7:236-241.

Tong ZK, Zeng YR, SI JP (2002). Variation, heredity and selection of effective ingredients in Magnolis officinalis of different provenances. J Forest Res 13:7-11.

Verzino G, Carranza C, Ledesma M, Joseau J, Di Rienzo J (2003). Adaptive genetic variation of Prosopis chilensis (Molina) Stuntz preliminary results from one test-site. Forest Ecol Manag 175:119-129.

Walter MB, Kruger EL, Reich PB (1993). Relative growth rate in relation to physiological and morphological traits for northern hardwood tree seedlings: species, light environment and ontogenetic considerations. Oecologia 96:219-231.

Westoby M, Flaster DS, Moles AT, Vesk PA, Wright IJ (2002). Plant ecological strategies: some leading dimensions of variation between species. Annu Rev Ecol Syst 33:125-159.

Zheng YL, Sun WB, Zhou Y, Coombs D (2009). Variation in seed and seedling traits among natural populations of Trigonobalanus doichangensis (A. Camus) Forman (Fagaceae), a rare and endangered plant in southwest China. New Forests 37:285-294.

Zohary D (2004). Unconscious selection and the evolution of domesticated plants. Econ Bot 58:5-10. 